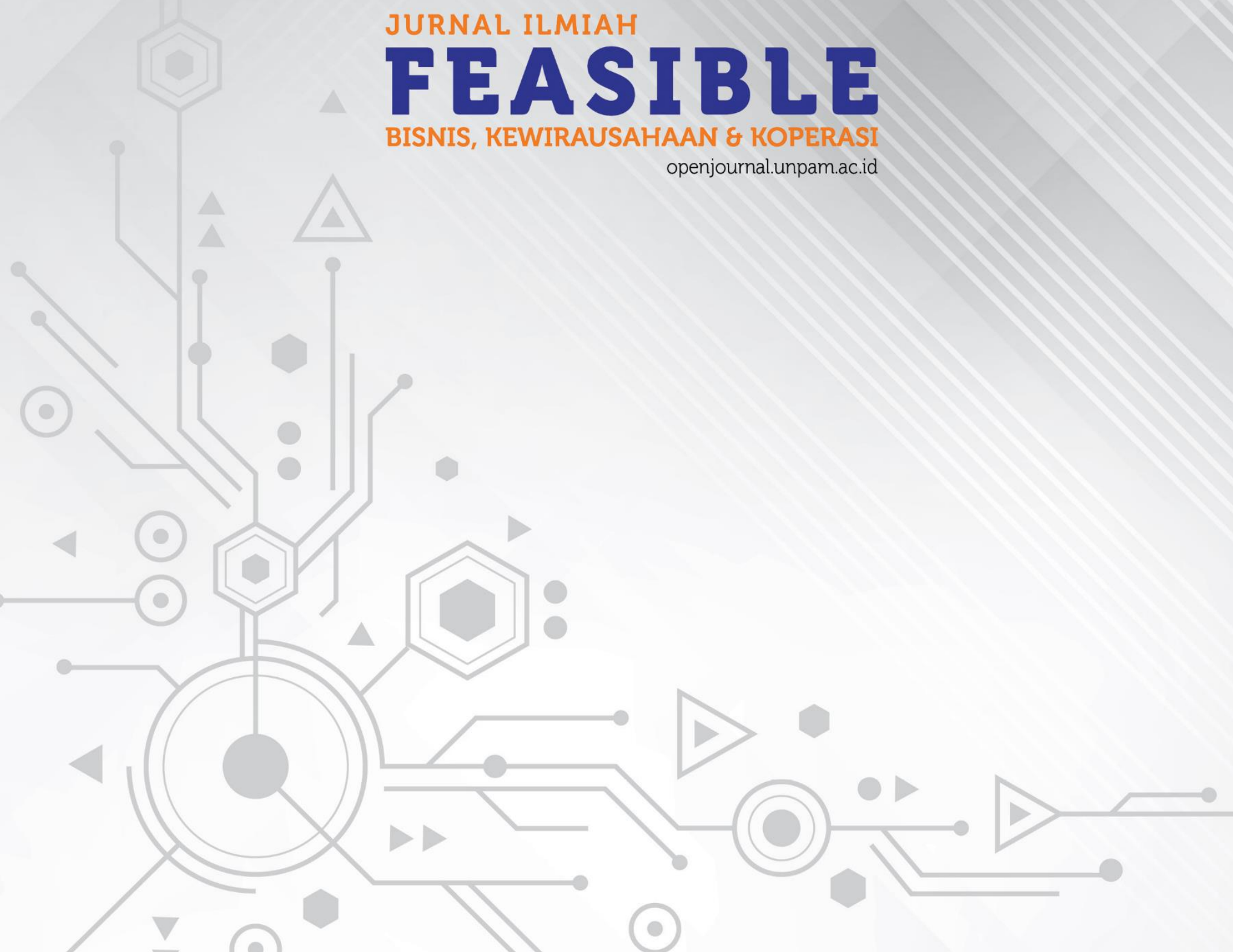


JURNAL ILMIAH FEASIBLE: Bisnis, Kewirausahaan \& Koperasi, Vol.2.No.1 Februari 2020: 83-94

P-ISSN : 2655-9811, E-ISSN : 2656-1964

J. Feasible., Vol. 2, No. 1, Februari 2020 (83-94)

C2019 Pusat Inkubasi Bisnis dan Kewirausahaan

Universitas Pamulang (PINBIK UNPAM)

\title{
PENGARUH HARGA DAN PROMOSI TERHADAP KEPUTUSAN PEMBELIAN PADA PT SARANA MULTIGRIYA LESTARI
}

\author{
Mutmainnah \\ Fakultas Ekonomi ; Universitas Pamulang \\ dosen01720@unpam.ac.id
}

\begin{abstract}
Abstrak
Penelitian ini bertujuan untuk mengetahui pengaruh secara parsial dan simultan antara Harga dan Promosi tehadap Keputusan Pembelian pada PT Sarana Multigriya Lestari. Metode penelitian ini adalah penelitian deskriptif kuantitatif. Populasi penelitian berjumlah 523 responden dan sampel berjumlah 84 responden menggunakan teknik random sampling. Metode analisa data menggunakan uji validitas, uji reliabilitas, uji koefisien korelasi product moment, uji koefisien determinasi, uji autokorelasi, uji heterokedastisitas, uji regresi linier berganda, dan uji hipotesis. Hasil penelitian secara parsial harga tidak berpengaruh terhadap keputusan pembelian dan promosi berpengaruh signifikan terhadap keputusan pembelian. Secara simultan Harga dan Promosi berpengaruh signifikan terhadap Keputusan Pembelian, dibuktikan dengan persamaan regresi $Y=5,388+0,224+0,675 X_{2}+$ $e$, koefisien Determinasi $R^{2}=0,655$ nilai f hitung 76,886 $>f$ tabel 3,11 dengan signifikansi $0,000<0,05$.
\end{abstract}

Kata Kunci : Harga, Promosi dan Keputusan Pembelian

\begin{abstract}
This study aims to determine the partial and simultaneous influence between Price and Promotion of Purchasing Decisions at PT Sarana Multigriya Lestari. This research method is quantitative descriptive research. The study population amounted to 523 respondents and a sample of 84 respondents using random sampling techniques. The data analysis method uses validity test, reliability test, product moment correlation coefficient test, coefficient of determination test, autocorrelation test, heterokedasticity test, multiple linear regression test, and hypothesis testing. The research results partially did not affect the purchase decision and promotion significantly influence the purchase decision. Simultaneously, Price and Promotion have a significant effect on Purchasing Decisions, as evidenced by the regression equation $Y=5.388+0.224+0.675 X \_2+e$, Determination coefficient $R 2=0.655$ calculated f value $76.886>$ ftable 3.11 with a significance of $0.000<0.05$.
\end{abstract}

Keywords : Price, Promotion and Purchasing Decisions

PENDAHULUAN

Latar Belakang
PT Sarana Multigriya Lestari (SML) merupakan sebuah perusahaan yang menjual barang-barang baja ringan dengan 
JURNAL ILMIAH FEASIBLE: Bisnis, Kewirausahaan \& Koperasi, Vol.2.No.1 Februari 2020: 83-94

menawarkan barang yang berbeda dibandingkan perusahaan lainnya. Pada perusahaan lainnya, umumnya menawarkan kualitas yang kurang baik. Namun pada PT SML justru memiliki kualitas barang yang baik, hal tersebut dikarenakan pada PT SML memiliki barang yang kuat dan tahan lama.

Tabel 1.1. Daftar Perbandingan Harga PT Sarana Multigriya Lestari dan PT KUS

\begin{tabular}{|r|l|r|r|}
\hline No & \multicolumn{1}{|c|}{$\begin{array}{c}\text { Nama Barang } \\
\text { PT SML }\end{array}$} & $\begin{array}{r}\text { Harga } \\
\text { PT KUS }\end{array}$ \\
\hline 1 & Hollow galvanis & 16.500 & 18.500 \\
\hline 2 & $\begin{array}{l}\text { Spandek pasir } \\
\text { merah }\end{array}$ & 63.000 & 60.000 \\
\hline 3 & Gypsum e-board & 46.500 & 43.000 \\
\hline 4 & Baut gypsum & 80.000 & 85.000 \\
\hline 5 & Baja sarana & 69.000 & 65.000 \\
\hline 6 & Channal & 69.000 & 63.000 \\
\hline 7 & Baut baja & 150.000 & 160.000 \\
\hline 8 & Besi beton & 59.000 & 70.000 \\
\hline 9 & Baja & 95.000 & 80.000 \\
\hline
\end{tabular}

Dari tabel di atas dapat diuraikan bahwa harga yang terdapat di PT Sarana Multigriya Lestari (PT SML) dan PT Karya Utama Sembada (PT KUS) mengalami perbandingan yang relatif sedikit. Pada PT SML harga yang ditawarkan pada daftar harga barang baja relatif lebih tinggi dibanding dengan PT KUS, sedangkan pada harga baut relatif lebih rendah dibandingkan dengan PT KUS. Kebijakan dalam penetapan harga yang dilakukan oleh perusahaan masih belum optimal, karena dengan kebijakan yang telah diberikan oleh perusahaan masih belum bisa bersaing, kebijakan yang telah diambil oleh perusahaan masih belum bisa menarik minat konsumen untuk membeli produk yang ditawarkan oleh perusahaan, dengan kata lain konsumen masih belum terpuaskan dengan harga yang ditetapkan oleh perusahaan.

Tabel 1.2. Tabel Penjualan Tahun 2018 PT Sarana Multrigriya Lestari

\begin{tabular}{|l|l|r|}
\hline No & Bulan & Pendapatan \\
\hline 1 & Januari & Rp. $94.641 .300,-$ \\
\hline 2 & Februari & Rp. 137.104.000,- \\
\hline 3 & Maret & Rp. $83.513 .500,-$ \\
\hline 4 & April & Rp. 170.273.580,- \\
\hline 5 & Mei & Rp. 230.667.700,- \\
\hline 6 & Juni & Rp. 265.545.500,- \\
\hline 7 & Juli & Rp. 240.832.300,- \\
\hline 8 & Agustus & Rp. 189.680.500,- \\
\hline 9 & September & Rp. 170.458.200,- \\
\hline 10 & Oktober & Rp. 210.534.600,- \\
\hline 11 & November & Rp. 227.863.000,- \\
\hline 12 & Desember & Rp. 167.768.600,- \\
\hline
\end{tabular}

Sumber : Laporan Penjualan PT Sarana Multigriya Lestari tahun 2018

Dari tabel di atas dapat dilihat bahwa pendapatan penjualan PT Sarana Multigriya Lestari mengalami pertumbuhan yang tidak menentu, pada bulan Februari terjadi peningkatan jumlah penjualan sebesar Rp. 42.462.700, namun pada maret mengalami penurunan sebesar Rp. 53.590.500, terjadi peningkatan pada bulan april sebesar Rp. 86.760.080, dan terjadi peningkatan pada bulan mei sebesar Rp.60.394.120 dan berikutnya. hal itu membuat perusahaan harus lebih memperhatikan aspek-aspek yang berpengaruh terhadap keputusan pembelian salah satunya adalah harga. Oleh karena itu diharapkan perusahaan dapat menyesuaikan harga terhadap kompetitor agar dapat bersaing dan meningkatkan keputusan pembelian.

Berdasarkan pada uraian latar belakang masalah yang terjadi di atas maka dapat diajukan sebuah penelitian dengan judul "Pengaruh Harga dan Promosi Terhadap Keputusan Pembelian Pada PT Sarana Multrigriya Lestari”. 
JURNAL ILMIAH FEASIBLE: Bisnis, Kewirausahaan \& Koperasi, Vol.2.No.1 Februari 2020: 83-94

\section{Perumusan Masalah}

Rumusan masalah dalam penelitian ini:

1. Bagaimana pengaruh harga terhadap keputusan pembelian pada PT Sarana Multigriya Lestari?

2. Bagaimana pengaruh promosi terhadap keputusan pembelian pada PT Sarana Multigriya Lestari ?

3. Bagaimana pengaruh harga dan promosi terhadap keputusan pembelian pada PT Sarana Multigriya Lestari?

\section{Tujuan Penelitian}

Secara eksplisit tujuan penelitian ini adalah:

1. Untuk mengetahui pengaruh harga terhadap keputusan pembelian pada PT Sarana Multigriya Lestari

2. Untuk mengetahui promosi terhadap keputusan pembelian pada PT Sarana Multigriya Lestari

3. Untuk mengetahui pengaruh harga dan promosi terhadap keputusan pembelian pada PT Sarana Multigriya Lestari

\section{Kerangka Berfikir}

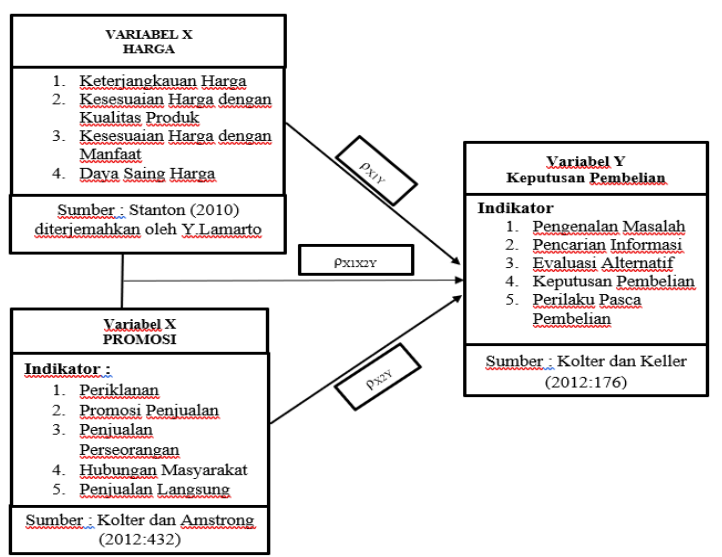

Gambar 1.1. Kerangka Berfikir

\section{Hipotesis}

H1 : Terdapat pengaruh yang signifikan antara harga terhadap keputusan pembelian PT Sarana Multigriya Lestari.

H2 : Terdapat pengaruh yang signifikan antara promosi terhadap keputusan pembelian PT Sarana Multigriya Lestari.

H3 : Terdapat pengaruh yang signifikan antara harga dan promosi terhadap keputusan pembelian PT Sarana Multigriya Lestari.

\section{Kajian Literatur}

\section{Harga}

Menurut Kolter dan Keller (2009:67) "harga adalah salah satu elemen bauran pemasaran yang menghasilkan pendapatan, elemen lain menghasilkan biaya. Harga merupakan elemen termudah dalam program pemasaran untuk disesuaikan, fitur produk, saluran, dan bahkan komunikasi membutuhkan banyak waktu”. Sedangkan menurut Alma (2013:169) "harga adalah nilai suatu barang yang dinyatakan dengan uang”. Dari kedua pengertian di atas, maka dapat disimpulkan bahwa harga adalah sejumlah uang yang harus dibayarkan untuk produk atau jasa, dan harga bisa berbedabeda tergantung dari produk atau jasa yang dijual.

\section{Promosi}

Menurut Lupiyoadi (2014:178) "kegiatan promosi bukan saja berfungsi sebagai alat komunikasi antara perusahaan dan konsumen melainkan juga sebagai alat untuk mempengaruhi konsumen dalam kegiatan pembelian atau penggunaan jasa sesuai dengan keinginan dan kebutuhan- 
JURNAL ILMIAH FEASIBLE: Bisnis, Kewirausahaan \& Koperasi, Vol.2.No.1 Februari 2020: 83-94

nya”. Promosi merupakan alat komunikasi yang digunakan oleh perusahaan untuk memperkenalkan barang dan jasa yang ditawarkan guna menarik konsumen untuk membeli dan menggunakan barang atau jasa yang ditawarkan tersebut.

\section{Keputusan Pembelian}

Menurut Setiadi (2010:331) mendefinisikan "suatu keputusan yaitu melibatkan pilihan antara dua atau lebih alternatif tindakan atau perilaku. Keputusan selalu mensyaratkan pilihan diantara beberapa perilaku yang berbeda”. Seorang konsumen yang hendak melakukan pilihan, maka ia harus memilih pilihan alternatif. Jika konsumen tidak memilih pilihan alternatif, maka hal tersebut bukan merupakan situasi konsumen melakukan keputusan. Menurut Kotler dan Amstrong (2012:157), “Consumer buyer behaviour refers to the buying behaviour of final consumer- individuals and households that buy goods and services for personal consumption", dari pengertian tersebut dapat diartikan bahwa perilaku keputusan pembelian mengacu pada perilaku pembelian akhir dari konsumen, baik individual, maupun rumah tangga yang membeli barang dan jasa untuk konsumsi pribadi.

\section{METODE}

\section{Ruang Lingkup Penelitian}

\section{Lokasi Penelitian}

Lokasi penelitian adalah tempat dimana peneliti melakukan penelitian untuk memperoleh data-data yang diperlukan.
Lokasi penelitian ini beralamat KP Ranca Gede RT 006/o01, Kelurahan Munjul Kecamatan Solear Kabupaten Tangerang Banten Indonesia.

2. Waktu Penelitian

Penelitian ini dilakukan di PT Sarana Multigriya Lestari (SMGL) dan pengambilan data dilakukan pada bulan Juni sampai Agustus 2019.

3. Ruang Lingkup Penelitian

Ruang lingkup penelitian ini adalah Menurut Sugiyono (2016:2) "metode penelitian pada dasarnya merupakan cara ilmiah untuk mendapatkan data dengan tujuan dan kegunaan tertentu”. Agar penelitian ini lebih terarah serta sesuai dengan tujuan yang diinginkan, penulis menggunakan metode penelitian deskriptif dengan pendekatan kuantitatif. Menurut Sugiyono (2016:35) mendefinisikan "metode deskriptif adalah metode yang digunakan untuk menggambarkan atau menganalisis suatu hasil penelitian tetapi tidak digunakan untuk membuat kesimpulan yang lebih luas". Menurut Sugiyono (2016:7) mendefinisikan "metode penelitian kuantitatif sebagai berikut: metode penelitian kuantitatif dapat diartikan sebagai metode penelitian yang berlandaskan pada filsafat positivism, digunakan untuk meneliti pada populasi atau sampel tertentu, pengumpulan data menggunakan instrumen penelitian, analisis data bersifat kuantitatif/statistik, dengan tujuan untuk menguji hipotesis yang telah ditetapkan”. 


\section{Populasi}

Dalam penelitian ini yang dijadikan populasi adalah pelanggan PT Sarana Multigriya Lestari (SML) berdasarkan sumber data transaksi penjualan pada bulan januari 2018 sampai dengan bulan desember 2018 sebanyak 523 Konsumen.

Tabel 1.3 Populasi Penelitian

\begin{tabular}{|c|c|}
\hline Bulan & Jumlah Konsumen \\
\hline Januari & 27 \\
\hline Februari & 30 \\
\hline Maret & 31 \\
\hline April & 47 \\
\hline Mei & 64 \\
\hline Juni & 66 \\
\hline Juli & 57 \\
\hline Agustus & 39 \\
\hline September & 37 \\
\hline Oktober & 42 \\
\hline November & 46 \\
\hline Desember & 37 \\
\hline
\end{tabular}

Sumber : Data Konsumen PT Sarana Multigriya Lestari tahun 2018

\section{Sampel}

Menurut Sugiyono (2010:116) "Sampel adalah sebagian dari jumlah dan karakteristik yang dimiliki oleh populasi tersebut. Metode penarikan sampel yang digunakan dalam penelitian ini adalah metode random sampling yaitu pengambilan sampel atau responden secara acak yang dianggap mampu mewakili dari populasi yang ada. Penulis menggunakan teknik pengambilan sampel yang digunakan untuk menentukan ukuran sampel yaitu menggunakan rumus Slovin (Syofian Siregar).

$$
\begin{aligned}
& \mathrm{n}=\frac{\mathrm{N}}{1+\mathrm{N} \cdot(\mathrm{e})^{2}} \\
& \mathrm{n}=\text { Sampel } \\
& \mathrm{N}=\text { pelanggan }
\end{aligned}
$$

$\mathrm{e}=$ Kesalahan dalam mengambil sampel yang ditetapkan sebesar 10\%

Ukuran sampel yang sesuai dengan rumus di atas:

$$
\begin{aligned}
& n=\frac{523}{1+523(0,1)^{2}} \\
& n=\frac{523}{1+523(0,01)} \\
& n=\frac{523}{1+5,24} \\
& n=\frac{523}{6,24} \\
& n=83,814 \\
& \text { Jadi berdasarkan perhitungan diatas, } \\
& \text { maka sampel yang digunakan dibulatkan } \\
& \text { menjadi } 84 \text { responden. }
\end{aligned}
$$

\section{HASIL dan PEMBAHASAN}

\section{Gambaran Umum Objek Penelitian}

PT Sarana Multigriya Lestari merupakan yang bergerak dibidang industri bahan bangunan yang berdiri pada tahun 2017, seiring perkembangan waktu PT Sarana Multigriya Lestari terus mengembangkan teknologi terkini dalam industri bahan bangunan. Diawal tahun 2018 PT Sarana Multigriya Lestari meluncurkan produk baru yang hadir dengan berkomitmen untuk selalu memberikan produk terbaik sesuai dengan mutu dan keamanan yang terbaik. PT Sarana Multigriya Lestari terletak KP Ranca Gede RT 006/o01, Kelurahan Munjul Kecamatan Solear Kabupaten Tangerang Banten Indonesia. Produk utama PT Sarana Multigriya Lestari adalah sistem rangka atap baja ringan dengan teknologi terkini hasil perkembangan secara konsisten dengan 
JURNAL ILMIAH FEASIBLE: Bisnis, Kewirausahaan \& Koperasi, Vol.2.No.1 Februari 2020: 83-94

menjamin kualitas kekuatan mutu dan struktural yang sesuai dengan standarstandar yang ada. Produk-produk yang dijual memiliki kualitas standar Indonesia yang telah diuji ketahanan dan keamanannya serta dapat diperjualbelikan kepada konsumen. PT Sarana Multigriya Lestari menjual beberapa produk industri bahan bangunan diantaranya Hollow galvanis, Spandek pasir merah, Gypsum eboard, Baut gypsum, Baja sarana, Channal, Baut baja, Besi beton dan Baja. Dari beberapa produk tersebut, baja ringan adalah produk utama yang diusung oleh PT Sarana Multigriya Lestari sebagai perusahaan yang bergerak dibidang industri bahan bangunan. Dari sekian banyaknya perusahaan yang bergerak dibidang yang sama, PT Sarana Multigriya Lestari mampu bersaing baik dilevel nasional maupun internasional dengan keunggulan yang dimiliki, seperti harga yang relatif murah, kualitas yang baik, atau pelayanan yang diberikan. Untuk dapat bersaing dengan perusahaan lain PT Sarana Multigriya Lestari akan terus berinovasi baik dari segi produk hingga kualitas produk serta pelayanan yang diberikan sehingga dapat menambah nilai bagi konsumen terhadap pelayanan yang diberikan.

\section{Karakteristik Responden}

Tabel 1.4. Karakteristik Responden Berdasarkan Jenis Kelamin

\begin{tabular}{|c|l|c|c|c|c|}
\hline \multicolumn{2}{|c|}{} & $\begin{array}{c}\text { Frequ } \\
\text { ency }\end{array}$ & $\%$ & $\begin{array}{c}\text { Valid } \\
\text { Percent }\end{array}$ & $\begin{array}{c}\text { Cumu } \\
\text { lative }\end{array}$ \\
\hline \multirow{3}{*}{ Valid } & Laki-laki & 48 & 48.0 & 48.0 & 48.0 \\
\cline { 2 - 6 } & Perempuan & 36 & 36.0 & 36.0 & 84.0 \\
\cline { 2 - 6 } & Total & 84 & 84.0 & 84.0 & \\
\hline
\end{tabular}

Dari data diatas berdasarkan jenis kelamin responden dapat diketahui bahwa yang berjenis kelamin laki-laki sebanyak $48 \%$ responden, dan yang berjenis kelamin perempuan sebanyak $36 \%$. Hal ini dapat digambarkan secara umum pelanggan PT Sarana Multigriya Lestari didominasi lakilaki

\begin{tabular}{|l|r|r|r|r|}
\hline \multicolumn{5}{|c}{ Tabel 1.5. Karakteristik Responden } \\
Berdasarkan Usia \\
\hline & $\begin{array}{c}\text { Frequ } \\
\text { ency }\end{array}$ & \multicolumn{1}{c|}{$\%$} & $\begin{array}{c}\text { Valid } \\
\text { Percent }\end{array}$ & $\begin{array}{l}\text { Cumu } \\
\text { lative }\end{array}$ \\
\hline$<25$ Tahun & 26 & 26.0 & 26.0 & 26.0 \\
\hline 26-40 Tahun & 52 & 52.0 & 52.0 & 78.0 \\
\hline$>$ 40 Tahun & 6 & 6.0 & 6.0 & 84.0 \\
\hline Total & 84 & 84.0 & 84.0 & \\
\hline
\end{tabular}

Sumber : Data Pengolahan SPSS versi 22

Dari hasil data diatas berdasarkan usia dapat diketahui bahwa responden dalam penelitian ini mayoritas pelanggan berusia < 25 tahun dengan jumlah 26\%, kemudian responden berusia 26-40 tahun dengan jumlah 52\%, dan pelanggan berusia $>40$ tahun dengan jumlah 6\%. Sehinggan dapat disimpulkan paling banyak pelanggan berusia 26 - 40 tahun.

Tabel 1.6 Karakteristik Responden Berdasarkan Pendidikan

\begin{tabular}{|c|l|r|r|r|r|}
\multicolumn{2}{|c|}{} & $\begin{array}{c}\text { Frequ } \\
\text { ency }\end{array}$ & \multicolumn{1}{c|}{$\%$} & $\begin{array}{c}\text { Valid } \\
\text { Percent }\end{array}$ & $\begin{array}{l}\text { Cumu } \\
\text { lative }\end{array}$ \\
\hline \multirow{7}{*}{ Valid } & S1 & 45 & 45.0 & 45.0 & 45.0 \\
\cline { 2 - 6 } & S2 & 4 & 4.0 & 4.0 & 49.0 \\
\cline { 2 - 6 } & D3 & 4 & 4.0 & 4.0 & 53.0 \\
\cline { 2 - 6 } & SMA/SMK & 31 & 31.0 & 31.0 & 84.0 \\
\cline { 2 - 6 } & Total & 84 & 84.0 & 84.0 & \\
\hline
\end{tabular}
\begin{tabular}{l|l|l|l} 
ency & $\%$ & Percent & lative
\end{tabular}

Sumber : Data Pengolahan SPSS versi 22

Dari data diatas sebanyak 45\% memiliki pendidikan S1, responden memiliki pendidikan S2 sebanyak 4\%, responden memiliki pendidikan D3 sebanyak 4\%, dan responden memiliki pendidikan SMA/SMK sebanyak 31\%. Dimana pelanggan yang mendominasi adalah responden yang memiliki pendidikan S1. 
JURNAL ILMIAH FEASIBLE: Bisnis, Kewirausahaan \& Koperasi, Vol.2.No.1 Februari 2020: 83-94

\section{Uji Validitas}

Tabel 1.7. Uji Validitas Variabel Harga (X1)

\begin{tabular}{|c|c|c|c|}
\hline \multicolumn{4}{|c|}{ Harga $\left(\boldsymbol{X}_{\mathbf{1}}\right)$} \\
\hline $\begin{array}{c}\text { No } \\
\text { Kuesioner }\end{array}$ & $\begin{array}{c}\text { Koefisien } \\
\text { Korelasi }\end{array}$ & $\mathbf{R}$ tabel & Keterangan \\
\hline 1 & 0,478 & 0,216 & Valid \\
\hline 2 & 0,563 & 0,216 & Valid \\
\hline 3 & 0,563 & 0,216 & Valid \\
\hline 4 & 0,547 & 0,216 & Valid \\
\hline 5 & 0,630 & 0,216 & Valid \\
\hline 6 & 0,695 & 0,216 & Valid \\
\hline 7 & 0,628 & 0,216 & Valid \\
\hline 8 & 0,564 & 0,216 & Valid \\
\hline
\end{tabular}

Sumber : Data Pengolahan SPSS versi 22

Tabel 1.8. Uji Validitas Variabel Promosi (X2)

\begin{tabular}{|c|c|c|c|}
\hline \multicolumn{4}{|c|}{ Promosi $\left(\boldsymbol{X}_{\mathbf{2}}\right)$} \\
\hline $\begin{array}{c}\text { No } \\
\text { Kuesioner }\end{array}$ & $\begin{array}{c}\text { Koefisien } \\
\text { Korelasi }\end{array}$ & R tabel & Keterangan \\
\hline 1 & 0,636 & 0,216 & Valid \\
\hline 2 & 0,684 & 0,216 & Valid \\
\hline 3 & 0,645 & 0,216 & Valid \\
\hline 4 & 0,570 & 0,216 & Valid \\
\hline 5 & 0,720 & 0,216 & Valid \\
\hline 6 & 0,734 & 0,216 & Valid \\
\hline 7 & 0,560 & 0,216 & Valid \\
\hline 8 & 0,809 & 0,216 & Valid \\
\hline 9 & 0,739 & 0,216 & Valid \\
\hline 10 & 0,754 & 0,216 & Valid \\
\hline
\end{tabular}

Sumber: Data Pengolahan SPSS versi 22.

Tabel 1.9. Uji Validitas Keputusan Pembelian (Y)

\begin{tabular}{|c|c|c|c|}
\multicolumn{4}{|c|}{ Keputusan Pembelian $(\mathbf{Y})$} \\
\hline $\begin{array}{c}\text { No } \\
\text { Kuesioner }\end{array}$ & $\begin{array}{c}\text { Koefisien } \\
\text { Korelasi }\end{array}$ & R tabel & Keterangan \\
\hline 1 & 0,586 & 0,216 & Valid \\
\hline 2 & 0,788 & 0,216 & Valid \\
\hline 3 & 0,734 & 0,216 & Valid \\
\hline 4 & 0,769 & 0,216 & Valid \\
\hline 5 & 0,794 & 0,216 & Valid \\
\hline 6 & 0,696 & 0,216 & Valid \\
\hline 7 & 0,699 & 0,216 & Valid \\
\hline 8 & 0,756 & 0,216 & Valid \\
\hline 9 & 0,783 & 0,216 & Valid \\
\hline 10 & 0,737 & 0,216 & Valid \\
\hline
\end{tabular}

Sumber: Data Pengolahan SPSS versi 22.

Berdasarkan ketiga tabel di atas maka dapat disimpulkan semua variabel dinyatakan valid, karena $\mathrm{r}$ hitung $>\mathrm{t}$ tabel.

\section{Uji Reliabilitas}

Tabel 1.10 Uji Reliabilitas

\begin{tabular}{c|c|c|c|c|} 
No & Variabel & $\begin{array}{c}\text { Alpha } \\
\text { Cronbach }\end{array}$ & Syarat & Ket. \\
\hline
\end{tabular}

\begin{tabular}{|c|l|c|c|c|}
\hline 1 & $\operatorname{Harga}\left(X_{1}\right)$ & 0,720 & 0,60 & Reliabel \\
\hline 2 & Promosi $\left(X_{2}\right)$ & 0,873 & 0,60 & Reliabel \\
\hline 3 & $\begin{array}{l}\text { Keputusan } \\
\text { Pembelian (Y) }\end{array}$ & 0,903 & 0,60 & Reliabel \\
\hline
\end{tabular}

Sumber : Data Pengolahan SPSS versi 22.

Berdasarkan tabel di atas dapat disimpulkan bahwa seluruh pernyataan dalam kuesioner dikatakan Reliabel dan baik sehingga dapat digunakan dalam penelitian ini.

\section{Uji Normalitas}

Tabel 1.11. Uji Normalitas

One-Sample Kolmogorov-Smirnov Test

\begin{tabular}{|llr|}
\hline & & \multicolumn{2}{|c|}{$\begin{array}{c}\text { Unstandardized } \\
\text { Residual }\end{array}$} \\
\hline $\mathrm{N}$ & & 84 \\
Normal & Mean & .0000000 \\
\hline $\begin{array}{l}\text { Most Extreme } \\
\text { Differences }\end{array}$ & Std. Deviation & 3.16425342 \\
\cline { 2 - 3 } & Absolute & .110 \\
\cline { 2 - 3 } Test Statistic & Negitive & .110 \\
\hline Asymp. Sig. (2-tailed) & -.097 \\
\hline \multicolumn{2}{|l|}{} & .110 \\
\hline
\end{tabular}

Dari hasil pengujian diperoleh nilai signifikansi sebesar 0,14 lebih besar dari 0,05 sehingga dapat disimpulkan bahwa data yang di uji berdistribusi normal.

\section{Uji Multikolinearitas}

Tabel 1.12. Hasil Uji Multikolinearitas Data Coefficients $^{\mathrm{a}}$

\begin{tabular}{|c|c|c|}
\hline \multirow{2}{*}{\multicolumn{2}{|c|}{ Model }} & Collinearity Statistics \\
\hline & & VIF \\
\hline \multirow[t]{3}{*}{1} & (Constant) & \\
\hline & $\mathrm{X} 1$ & 1.541 \\
\hline & $\mathrm{X} 2$ & 1.541 \\
\hline
\end{tabular}

a. Dependent Variable: Y

Berdasarkan tabel diatas dapat diketahui bahwa nilai VIF $=1.541$ artinya nilai VIF ini lebih kecil dari $10(1.541<10)$. 
JURNAL ILMIAH FEASIBLE: Bisnis, Kewirausahaan \& Koperasi, Vol.2.No.1 Februari 2020: 83-94

\begin{tabular}{|c|c|c|c|c|c|}
\hline & \multirow{2}{*}{ Model } & \multicolumn{2}{|c|}{$\begin{array}{l}\text { Unstandardized } \\
\text { Coefficients }\end{array}$} & \multirow[t]{2}{*}{$\mathrm{t}$} & \multirow[t]{2}{*}{ Sig. } \\
\hline & & B & $\begin{array}{l}\text { Std. } \\
\text { Error }\end{array}$ & & \\
\hline \multirow{3}{*}{1} & (Constant) & 5.388 & 3.146 & 1.713 & .091 \\
\hline & $\mathrm{X} 1$ & .224 & .121 & 1.848 & .068 \\
\hline & $\mathrm{X} 2$ & .675 & .077 & 8.782 & .000 \\
\hline
\end{tabular}

\section{Uji Heterokedastisitas}

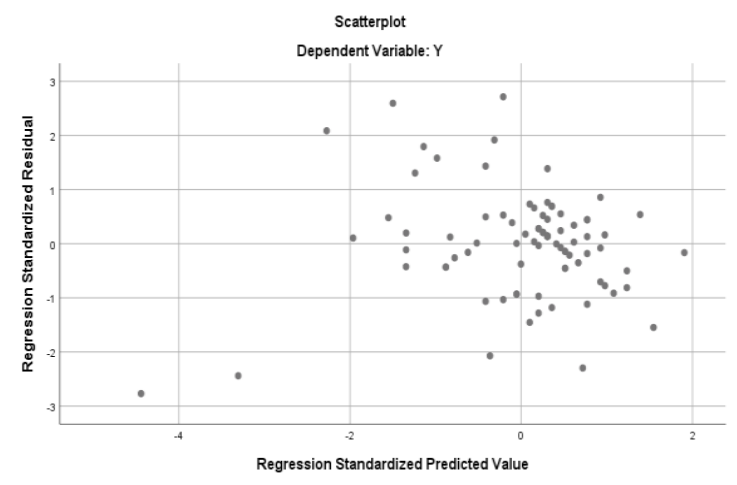

Gambar 1.2. Hasil Uji Heterokedastisitas

Dari scatterplot tersebut, terlihat bahwa titik-titik menyebar secara acak, baik dibagian atas nol atau bagian bawah angka nol dari sumbu vertikal atau sumbu Y. Dengan demikian, dapat disimpulkan bahwa titik tidak terjadi Heterokedastisitas dalam model regresi.

\section{Uji Autokorelasi}

\section{Gambar 1.13. Hasil Uji Autokorelasi}

\begin{tabular}{|c|c|c|c|}
\multirow{2}{*}{ Model } & \multicolumn{3}{|c|}{ Change Statistics } \\
\cline { 2 - 4 } & df2 & Sig. F Change & LM \\
\hline 1 & 81 & .000 & 2.151 \\
\hline
\end{tabular}

Berdasarkan hasil pengujian pada tabel diatas, model regresi ini tidak terdapat autokorelasi, hal ini dibuktikan dengan nilai $L M$ sebesar 2.151 dikarenakan nilai $2.151>$ 0,05 .

\section{Uji Regresi Linier Berganda}

Tabel 1.14.Hasil Uji Regresi Linier Berganda

a. Dependent Variable: $\mathrm{Y}$

Berdasarkan tabel diatas diperoleh persamaan regresi linear berganda sebagai berikut: $\mathrm{Y}=5,388+0,224+0,675 \mathrm{X}_{2}+\mathrm{e}$ Persamaan regresi tersebut mempunyai makna:

1. Konstanta sebesar 5,833 menyatakan bahwa tanpa ada variabel Strategi Harga (X1) dan Promosi (X2) maka Keputusan Pembelian (Y) tetap terbentuk sebesar 5,388 atau jika Harga (X1) dan Promosi (X2) nilainya $=0$ maka Keputuan Pembelian tetap memiliki nilai 5,388. Yang artinya pelanggan akan tetap memnbeli produk PT Sarana Multigriya Lestari meskipun Harga dan Promosi yang diberikan masih kurang, karena pada dasarnya pelanggan menginginkan barang yang ada pada PT Sarana Multigriya Lestari.

2. Variabel Harga (X1) berpengaruh positif terhadap keputusan pembelian (Y) dengan nilai koefisien sebesar 0,224. Artinya jika variabel Harga (X1) meningkat satu-satuan dengan asumsi bahwa varibel Promosi (X2) tetap, maka keputusan pembelian (y) akan meningkat sebesar 0,224.

3. Variabel Promosi (X2) berpengaruh positif terhadap keputusan pembelian (y) dengan nilai koefisien sebesar 0,675. Artinya jika variabel promosi (X2) meningkat satu-satuan dengan asumsi bahwa variabel harga (X1) tetap, maka 
JURNAL ILMIAH FEASIBLE: Bisnis, Kewirausahaan \& Koperasi, Vol.2.No.1 Februari 2020: 83-94

keputusan pembelian (y) akan

meningkat sebesar 0,675 .

\section{Uji Koefisien Determinasi}

Tabel 1.15. Hasil Uji koefisien Determinasi

\begin{tabular}{|l|r|r|r|r|}
\hline Model & $\mathrm{R}$ & $\begin{array}{c}\mathrm{R} \\
\text { Square }\end{array}$ & $\begin{array}{c}\text { Adjusted R } \\
\text { Square }\end{array}$ & $\begin{array}{l}\text { Std. Error } \\
\text { of the } \\
\text { Estimate }\end{array}$ \\
\hline 1 & $.809^{\mathrm{a}}$ & .655 & .646 & 3.203 \\
\hline
\end{tabular}

Sumber : Data Pengolahan SPSS versi 22

Berdasarkan tabel di atas hasil perhitungan dapat diketahui bahwa koefisien determinasi (Rsquare) yang diperoleh sebesar o,655 atau 65,5\%. Artinya Harga (X1) dan Promosi (X2) secara bersamasama berkonstribusi terhadap Keputusan pembelian (Y) PT Sarana Multigriya Lestari sebesar $65,5 \%$. Dan sisanya sebesar $34,5 \%$ dipengaruhi oleh variabel-variabel lain yang tidak diteliti.

\section{Uji Parsial (Uji t)}

Tabel 1.16. Hasil Uji Parsial (uji t)

\begin{tabular}{|c|c|c|c|c|}
\hline \multirow[b]{2}{*}{ Model } & \multicolumn{2}{|c|}{$\begin{array}{c}\text { Unstandardized } \\
\text { Coefficients }\end{array}$} & \multirow[t]{2}{*}{$\mathrm{T}$} & \multirow[t]{2}{*}{ Sig. } \\
\hline & B & Std. Error & & \\
\hline 1 (Constant) & 5.388 & 3.146 & 1.713 & .091 \\
\hline $\mathrm{X} 1$ & .224 & .121 & 1.848 & .068 \\
\hline $\mathrm{X} 2$ & .675 & .077 & 8.782 & .000 \\
\hline
\end{tabular}

a. Dependent Variable: Y

Pengaruh dari masing-masing variabel (X1) dan (X2) terhadap (Y) dapat dilihat dari arah tanda dan tingkat signifikansi (probabilitas) dimana semua variabel memiliki arah yang positif dan berpengaruh signifikan karena nilai signifikansi kurang dari 0,05. Atau pada $t$ tabel dengan nilai siginfikansi o,o maka diperoleh : Hasil uji parsial atau uji t antara harga terhadap keputusan pembelian menunjukkan nilai t hitung lebih besar dari t tabel $(1,848>1,664)$ dan sig 0,68 < 0,05, sehingga Ho ditolak dan Ha diterima yaitu "terdapat pengaruh harga terhadap keputusan pembelian pada PT Sarana Multigriya Lestari”. Hasil uji parsial atau uji $\mathrm{t}$ antara promosi terhadap keputusan pembelian menunjukkan nilai thitung lebih besar dari t tabel $(8,782>1,664)$ dan sig 0,000 < 0,05, sehingga Ha diterima dan Ho ditolak yaitu "terdapat pengaruh promosi terhadap keputusan pembelian pada PT Sarana Multigriya Lestari”.

\section{Uji Simultan (Uji F)}

Tabel 1.16 Uji Simultan (Uji F)

\begin{tabular}{|ll|c|c|}
\hline Model & F & Sig. \\
\hline 1 & Regression & 76.886 & $.000^{\mathrm{b}}$ \\
\cline { 2 - 3 } & Residual & & \\
\hline
\end{tabular}

Dari hasil uji $\mathrm{F}$ dapat diperoleh nilai $\mathrm{F}$ hitung $>$ F tabel, yaitu 76,886 > 3,11 dan sig $0,000<0,05$ sehingga terdapat pengaruh harga dan promosi secara simultan terhadap keputusan pembelian pada PT Sarana Multigriya Lestari.

\section{SIMPULAN}

\section{Kesimpulan}

Berdasarkan hasil analisis dan pembahasan maka dapat diambil kesimpulan sebagai berikut :

1. Pengaruh harga terhadap keputusan pembelian berdasarkan hasil analisis data menunjukkan harga berpengaruh positif terhadap keputusan pembelian, hal ini dibuktikan dengan hasil uji 
validitas $\mathrm{r}$ hitung $(0,478)>\mathrm{r}$ tabel $(0,300)$ berarti butir pernyataan nomor satu yaitu harga (X1) dinyatakan valid. Hasil uji reliabilitas rca $(0,720)>r$ tabel (o,600) dengan ketentuan $\alpha=5 \%$ maka besar $\mathrm{r}$ tabel $=0,6$ artinya, hasil kuesioner variabel harga (X1) dinyatakan Reliabel. Hasil uji hipotesis secara simultan menunjukkan nilai $\mathrm{t}$ hitung $>\mathrm{t}$ tabel $(1,848>1,664)$ dan sig < 0,05 $(0,68<0,05)$ maka Ha ditolak Ho diterima yang artinya terdapat pengaruh positif yang signifikan antara harga terhadap keputusan pembelian pada PT Sarana Multigriya Lestari.

2. Pengaruh promosi terhadap keputusan pembelian berdasarkan hasil analisis data menunjukkan promosi berpengaruh positif terhadap keputusan pembelian, hal ini dibuktikan dengan hasil uji validitas $\mathrm{r}$ hitung $(0,636)>\mathrm{r}$ tabel $(0,300)$ berarti butir pernyataan nomor dua yaitu promosi (X2) dinyatakan valid. Hasil uji reliabilitas rca $(0,873)>r$ tabel (o,600) dengan ketentuan $\alpha=5 \%$ maka besar $\mathrm{r}$ tabel $=0,6$ artinya, hasil kuesioner variabel promosi (X2) dinyatakan Reliabel. Hasil uji hipotesis secara simultan menunjukkan nilai $\mathrm{t}$ hitung > t tabel $(8,782>1,664)$ dan sig < 0,05 $(0,000<0,05)$ maka Ha ditolak Ho diterima yang artinya terdapat pengaruh positif yang signifikan antara promosi terhadap Keputusan Pembelian pada PT Sarana Multigriya Lestari.

3. Pengaruh harga dan promosi terhadap keputusan peembelian berdasarkan hasil analisis data menunjukkan harga dan promosi berpengaruh positif terhadap keputusan pembelian, hal ini dibuktikan dengan hasil uji validitas $r$ hitung $(0,586)$ $>$ r tabel $(0,300)$ berarti butir pernyataan nomor tiga yaitu Keputusan pembelian (Y) dinyatakan valid. Hasil uji reabilitas rca $(0,903)>r$ tabel $(0,600)$ dengan ketentuan $\alpha=5 \%$ maka besar $r$ tabel $=$ o,6 artinya, hasil kuesioner variabel Keputusan Pembelian (Y) dinyatakan Reliabel. Hasil regresi linier berganda $\mathrm{Y}$ $=5,388+0,224+0,675 \mathrm{X}_{2}+\mathrm{e}$ dengan konstanta sebesar 5,388 menyatakan bahwa tanpa ada variabel harga (X1) dan promosi (X2) maka keputusan pembelian (Y) tetap terbentuk sebesar 5,388 atau jika harga $(\mathrm{X} 1)$ dan promosi (X2) nilainya $=0$ maka keputusan pembelian tetap memiliki nilai 5,388 . Hasil koefisien Determinasi $\mathrm{R}^{2}=0,655$, artinya variabel harga (X1) dan promosi (X2) memiliki kontribusi sebesar 65,5\% terhadap keputusan pembelian (Y) dan sisanya $34,5 \%$ dipengaruhi variabel lain. Hasil uji hipotesis secara simultan menunjukjan nilai f hitung $>$ f tabel yaitu $76,886>3,11$ dan sig < 0,05 atau 0,000 $<0,05$ Ha ditolak Ho diterima yang artinya terdapat pengaruh positif yang signifikan antara harga dan promosi terhadap keputusan pembelian pada PT Sarana Multigriya Lestari.

\section{Saran}

Berdasarkan hasil analisis dan kesimpulan penelitian di atas, maka dapat dikemukakan 
beberapa saran sebagai berikut:

1. Pada variabel Harga (X1) skor terendah ada pada pernyataan no. 4 yaitu "Kualitas produk besi beton telah sesuai dengan harga yang ditentukan”. Karena diperoleh skor terendah 3,85. Maka PT Sarana Multigriya Lestari harus meningkatkan kualitas pada produk besi beton yang sesuai dengan harga yang telah ditentukan..

2. Pada variabel Promosi (X2) skor terendah ada pada pernyataan no. 2 yaitu "Iklan mengenai produk telah tersebar dimedia massa (internet, media sosial dan brosur)". Karena diperoleh skor terendah 3,54. Maka PT Sarana Multigriya Lestari harus meningkatkan perikalan agar masyarakat mengetahui produk yang ada di PT Sarana Multigriya Lestari”.

3. Pada variabel Keputusan Pembelian (Y) skor terendah ada pada pernyataan no. 10 yaitu "Saya akan selalu membeli produk yang ada di PT Sarana Multigriya Lestari”. Karena diperoleh skor terendah 3,52. Maka PT Sarana Multigriya Lestari harus mementingkan keinginan pelanggan agar pelanggan dapat memutuskan untuk membeli barang yang ada di PT Sarana Multigriya Lestari.

4. Bagi peneliti selanjutnya, penulis berharap tulisan ini dapat menjadi referensi dan dapat menambahkan variabel bagi penelitian berikutnya, sehingga penelitian ini dapat bermanfaat bagi dunia akademis khususnya dan bagi masyarakat pada umumnya.

\section{DAFTAR PUSTAKA}

Alma, Buchari. 2013. Manajemen Pemasaran dan Pemasaran Jasa. Penerbit : Alfabeta, Bandung

Danang, Sunyoto, 2012. Manajemen Sumber Daya Manusia. Jakarta: PT Buku Seru

Danang, Sunyoto, 2013. Manajemen Pemasaran. Jakarta: PT Buku Seru

Kolter Dan Kevin Lane Keller. 2009. Manajemen Pemasaran. Edisi 13. Jakarta : Erlangga

Kolter, Philip and Gary Armstrong. 2012. Prinsip-prinsip pemasaran. Edisi 13. Jilid 1. Jakarta : Erlangga

Kolter dan Kevin Lane Keller. 2012, Marketing Management 14th Edition. New Jersey : Pearson Education, Inc

Kolter dan Keller, 2012, Marketing Management. Edisi 14 Global Edition. Pearson, Prenice Hall

Kolter, Philip and Gary Armstrong. 2012. Prinsip-prinsip Pemasaran. Edisi. 13. Jilid 1. Jakarta : Erlangga

Lupiyoadi, Rambat. 2014. Manajemen Pemasaran Jasa Berbasis Kompetensi. Edisi ke 3. Jakarta : Salemba Empat

Setiadi, Nugroho J. 2010. Perilaku Konsumen. Jakarta : Kencana

Sugiyono. 2016. Metodologi Penelitian Kuantitatif, Kualitatif,dan $R \& D$. Bandung : Alfabeta 
JURNAL ILMIAH FEASIBLE: Bisnis, Kewirausahaan \& Koperasi, Vol.2.No.1 Februari 2020: 83-94

Sugiyono, 2010. Metode Penelitian Bisnis.

Bandung. Alfabeta

Tjiptono, Fandy. 2014. Pemasaran Jasa

(Prinsip, Penerapan, Penelitian).

Yogyakarta Andi. 